\title{
Neighborhood Social Conditions Mediate the Association Between Physical Deterioration and Mental Health
}

\author{
Daniel J. Kruger · Thomas M. Reischl • \\ Gilbert C. Gee
}

Published online: 9 October 2007

(C) Springer Science+Business Media, LLC 2007

\begin{abstract}
This study investigates how neighborhood deterioration is associated with stress and depressive symptoms and the mediating effects of perceived neighborhood social conditions. Data come from a community survey of 801 respondents geocoded and linked to a systematic on-site assessment of the physical characteristics of nearly all residential and commercial structures around respondents' homes. Structural equation models controlling for demographic effects indicate that the association between neighborhood deterioration and well-being appear to be mediated through social contact, social capital, and perceptions of crime, but not through neighborhood satisfaction. Specifically, residential deterioration was mediated by social contact, then, social capital and fear of crime. Commercial deterioration, on the other hand, was mediated only through fear of crime. Additionally, data indicate that the functional definition of a "neighborhood" depends on the characteristics measured. These findings suggest that upstream interventions designed to improve neighborhood conditions as well as proximal interventions focused on social relationships, may promote well-being.
\end{abstract}

Keywords Neighborhood deterioration - Social capital Fear of crime $\cdot$ Mental health

At the time of this study, Dr. Gee was at the University of Michigan.

D. J. Kruger $(\bowtie) \cdot$ T. M. Reischl

University of Michigan, 1420 Washington Heights, M2523,

Ann Arbor, MI 48106-1248, USA

e-mail:djk2012@gmail.com

G. C. Gee

University of California, Los Angeles, USA

\section{Introduction}

Although mental health is typically assessed at the individual level, researchers have long noted that higher level factors (e.g., family, community) can impact mental health (Furstenburg 1993; Huckfeldt 1983; Hunter 1974). The "Chicago School" of sociology emphasized the impact of neighborhood physical decay on mental health problems (e.g., Park and Burgess 1925). For example, Chicago School researchers Faris and Dunham (1939) noted that socially disorganized areas had higher rates of psychoses.

There are several theoretical models of how neighborhood conditions could affect mental health (see Wandersman and Nation 1998). The environmental stress model connects aspects of the physical environment and individual mental health outcomes, as moderated by successful and unsuccessful coping (Baum et al. 1981; Wandersman et al. 1983). The neighborhood disorder model suggests that social incivilities (e.g., public drunkenness, street harassment) and physical incivilities (e.g., abandoned buildings, dilapidated housing) affect crime rates and fear of crime (e.g., Taylor et al. 1985). Fear of crime could in turn impact residents' mental health (Wandersman and Nation 1998; White et al. 1987). Kawachi et al. (1999) argue that neighborhood social capital leads to poor health directly and indirectly via neighborhood crime. Guided by these theoretical models, the research on neighborhood effects on mental health has focused on both individual perceptions of one's neighborhood as well as the social and physical characteristics of these neighborhoods.

Living in deteriorating neighborhoods may have both direct and indirect effects on the experience of stress (Gee and Payne-Sturges 2004). An individual in a deteriorating neighborhood may directly experience the stress associated 
with living in a residence needing repairs, exposing the individual to extreme temperatures, damaged appliances and fixtures (e.g., lighting, plumbing), and to potentially dangerous conditions such as exposed nails or peeling paint. If an individual lives near deteriorating buildings, the indirect effects could include the strain of living in a neighborhood with declining home values, concerns with safety and crime associated with living near abandoned or damaged properties, and concerns with high resident turnover that often occurs in economically depressed neighborhoods.

Both the direct and indirect effects of living in deteriorating neighborhoods, however, are likely mediated by the cognitive appraisal of neighborhood conditions. Lazaraus and others (Lazarus 1999; Lazarus and Folkman 1984; Sandler et al. 1997) suggest that the experience of stress is mediated by the appraisal of stressors and of coping resources, which include supportive social relationships. In the present study we examine how the physical condition of neighborhood properties is related to mental health with a specific focus on the mediating role of perceptions of neighborhood social conditions and individuals' fear of crime.

\section{Neighborhood Social Conditions}

The perception of social and community conditions in one's neighborhood has been tied to mental health outcomes. Aneshensel and Sucoff (1996) found that depression among youth is associated with lower levels of social cohesion. Consistent with Sarason's (1974, p. 1) definition of community as "the sense that one was part of a readily supportive network of relationships," relations with neighbors and social support from interactions with neighbors are strongly related to the subjective sense of community (Prezza et al. 2001). Support from social networks is related to lower levels of child abuse, even in neighborhoods with high concentrated poverty (Garbarino and Kostelny 1992).

\section{Neighborhood Physical Conditions}

In addition to social factors, physical indicators of neighborhood decline are believed to impact on health and mental health (Wandersman and Nation 1998). Higher noise levels in neighborhoods are associated with lower academic achievement (Bronzaft and McCarthy 1975), less upkeep of yards, and a greater number of arrests (Damon 1977). Cohen et al. (2000) found that an index of housing quality, abandoned cars, graffiti, trash, and public school deterioration explained more of the variance in gonorrhea rates than did a poverty index measuring income, unemployment, and low education. High concentrations of apartments of 4 or more stories are associated with lower sense of community, possibly because of the barriers to social interaction (Weenig et al. 1990).

\section{Fear of Crime}

The link between residential conditions and health may be partially mediated by fear of crime. Several studies have examined the association between neighborhood physical condition and residents' fear of crime (e.g., Box et al. 1988; Lewis and Maxfield 1980; Perkins and Taylor 1996; Skogan and Maxfield 1981). Deteriorating neighborhood structures might be associated with concerns over safety (Austin et al. 2002) because these physical cues may be seen as an indicator of a lack of social control (Ross and Mirowsky 1999). Greater satisfaction with one's neighborhood environment is also related to greater perceptions of neighborhood safety (Baba and Austin 1989).

Crime is associated with social capital (Sampson 1995). Interpersonal trust among community members is part of the core definition of social capital (Coleman 1990; Putnam 1993). Greater trust of neighbors is related to lower rates of homicide, assault, robbery, and burglary (Kawachi et al. 1999). Further, social capital may mediate the association between crime and health (Sampson et al. 1999). Sampson et al. (1997) found that collective efficacy significantly attenuated perceptions of crime in Chicago. Fostering collective efficacy to control neighborhood crime may have beneficial effects on mental health (Browning and Cagney 2002).

\section{Enhanced Neighborhood Measures}

In their review of the literature on the impact of neighborhoods on youth and adolescents, Leventhal and BrooksGunn (2003) recommend moving beyond census measures of SES to directly assessing underlying neighborhood problems. The suggested methods include systematic observations of a neighborhood's social and physical features and community surveys that interview neighborhood residents otherwise uninvolved in research or intervention projects. The census tract is a rather large unit of analysis; it often contains several distinct neighborhoods and is not necessarily representative of neighborhood boundaries (Farrell et al. 2004). Because heterogeneity within census tracts may present problems for analysis of neighborhood effects, smaller homogeneous neighborhoods may be more useful units of analysis (Wiesenfeld 1996). 
Researchers have also investigated the connection between perceptions of neighborhood safety to the actual conditions of neighborhood physical structures (e.g., Taylor 2001). For example, using systematic neighborhood observations on a standardized rating system and a telephone survey, Austin et al. (2002) found that housing quality affects satisfaction with the local physical environment, which in turn was related to perceptions of neighborhood safety. Housing quality also had a direct effect on perceptions of neighborhood safety. Thus, it is important to measure both residents' perceptions of their neighborhoods as well as the objective characteristics of these neighborhoods.

\section{Current Hypotheses}

This study attempts to integrate theoretical components, previous findings, and research recommendations on the relationships between neighborhood physical conditions, social conditions, and mental health in a single model. We combine measures of neighborhood physical conditions, perceptions of neighborhood social conditions, and individual levels of stress and depressive symptoms. Following recommendations by Leventhal and Brooks-Gunn (2003), we use data from a large scale community survey of nonstudy participants and a systematic assessment of the physical condition of all the structures in Flint, Michigan, USA. We anticipate that neighborhood physical deterioration will impact on community social conditions and residents' perceptions of these conditions, including protective factors such as social interaction and social capital, and aversive factors such as fear of crime. We suggest that social contact with neighbors and perceptions of neighborhood social capital may influence satisfaction with one's neighborhood and fear of crime, which will be the proximal factors affecting stress and depressive symptoms. We also consider the possibility of a direct impact of social contact with neighbors and perceptions of neighborhood social capital on stress and depressive symptoms.

Separate pieces of this model have been examined in previous studies; however we believe that it is important to examine the path of causality between physical conditions, social and community perceptions, and mental health outcomes all in one study. This also enables a test for a direct effect of neighborhood physical conditions, in addition to effects mediated by perceptions of the social environment (See Fig. 1). We also test an alternative framework for the causal pathway between neighborhood deterioration and mental health outcomes. Skogan (1991) proposed a feedback process where fear of crime leads to psychological withdrawal from community life, and the decline in social involvement leads to a cycle of increasing crime and decreasing social capital. Our second model depicts a process where neighborhood social contact predominantly mediates the impact of fear of crime and declining social capital on mental health outcomes (see Fig. 2). Although our cross-sectional data cannot provide a true test of Skogan's (1991) model, we use elements of this model to test an alternative framework of causality.

\section{Setting}

Flint, Michigan is an industrial city whose population grew and declined during the 20th century with the manufacturing capacity of the city's largest employer, General Motors. In 1970, GM employed an estimated 80,000 workers at Flint area plants. GM currently employs under 15,000 area workers. As these jobs left the area, so did a significant portion of Flint's population, declining $36.5 \%$ from 196,940 in 1970 to 124,943 in 2000 . The city of Flint also has experienced higher unemployment rates than most urban centers in the State of Michigan. The development of a strong manufacturing economy during the 1950s and 1960s helped produce the financial support for the development of Flint's educational and cultural institutions, but recent losses in the city's property tax base has led to budget cuts for the city government and for the city's public schools. Although crime decreased in the city during the 1990s, Flint still ranks high in rates of violent and nonviolent crime in Michigan and in the U.S. (FBI, 2000).

\section{Method}

\section{Telephone Survey Procedures}

The Prevention Research Center of Michigan's (PRC/MI) Speak to Your Health! Community Survey was developed through a collaborative process by a Survey Committee composed of members from the University of Michigan's School of Public Health, the Genesee County Health Department, the Greater Flint Health Coalition, University of Michigan-Flint, and the Flint Odyssey House Health Awareness Center. The survey was designed to monitor and understand community health and community concerns, monitor the impact of PRC/MI and other health initiatives on community health outcomes, and promote change that improves the health of Genesee County communities. The response rate for the telephone sample was $15 \%$.

To ensure that the survey respondents represented all geographic regions of Flint and Genesee County, random samples of households were drawn from Genesee County Census Tracts. At least 20 residents were obtained for each 
Fig. 1 Model 1, unique standardized predictions controlling for demographic factors

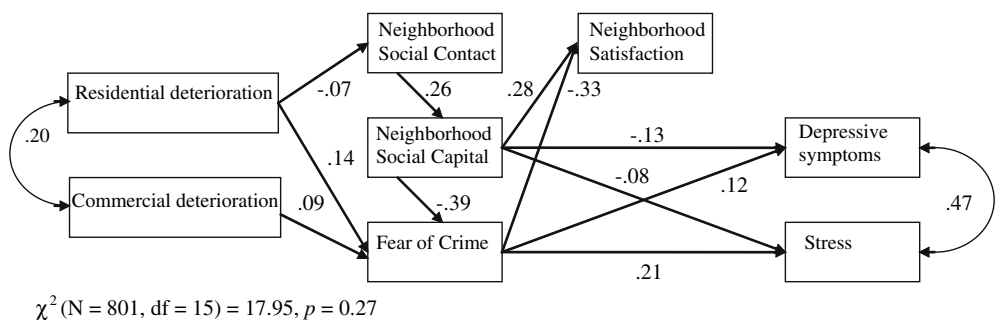

Fig. 2 Model 2, unique standardized predictions controlling for demographic factors

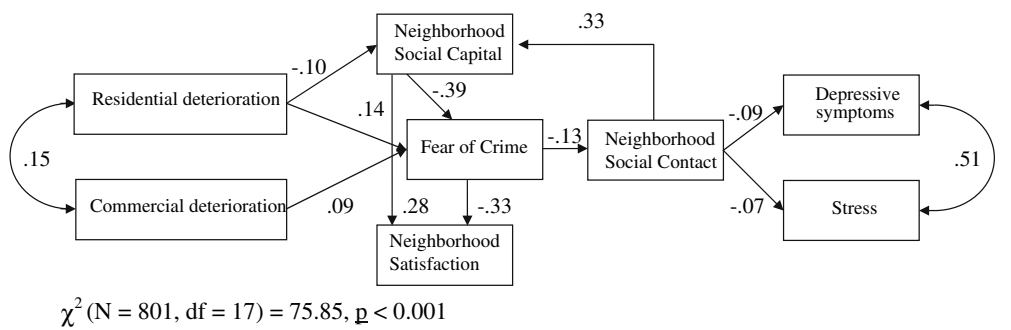

of the 39 residential Census Tracts in the city of Flint (two Census Tracts in Flint had few or no households) and at least 10 from each of the 90 Census Tracts outside of Flint. Although we noted the limitations of census tracts for analytic purposes, we used tracts as a practical way to sample respondents; in particular, tracts provide a replicable sampling frame that helped to facilitate geographic dispersion of respondents across the county. However, as shown below, the geographic unit of analysis for this study will not be based on census tracts.

\section{Telephone Survey Sample}

We focus our analyses on Flint residents because the Environmental Block Assessment, providing data on the physical deterioration of residential and commercial buildings (see below), was conducted in the city of Flint. Of the 838 respondents living in Flint, 37 identified with a race group other than African American or White. Because there were insufficient sample sizes for inclusion of respondents from other races/ethnicities, our analyses utilized data only from the 801 respondents who selfidentified as African American or White. Of these respondents, $69 \%$ were female, $38 \%$ were married, $57 \%$ were African American, and 18\% were unemployed. Education attainments of respondents 25 years and older were: $12 \%$ less than High School, 33\% High School graduate, $32 \%$ technical school or some college, $10 \%$ Associates Degree, 8\% Bachelor's Degree, and 5\% Master's Degree or higher. Respondents' ages ranged from 18 to 100 years, with a median of $45(M=45, S D=17$. In 2000, the population of Flint was 53\% female, 53\% African American, $41 \%$ White, and the median age was 31 . (U.S. Census 2001a). Education attainments of residents
25 years and older were: $25 \%$ less than High School, 32\% High School graduate, $24 \%$ technical school or some college, 6\% Associates Degree, 7\% Bachelor's Degree, and 4\% Master's Degree or higher (U.S. Census 2001b). We note that we under-represent those with less than a high school level of education. Missing values (3\%) were imputed using the linear trend predictions from other variables in the analysis.

\section{Telephone Survey Measures}

Neighborhood social capital was assessed with two items used in previous studies (Sampson et al. 1997; Ellen et al. 2004) where respondents indicated the degree to which people in their neighborhood could be trusted and were willing to help their neighbors (Cronbach's alpha $=.76$ ). Respondents' satisfaction with the quality of life in their neighborhood and degree of social contact with their neighbors were each assessed with one item (also from Sampson et al. 1997). Perceptions of neighborhood crime and safety were assessed with a four item scale (from Smith et al. 1999); the items were "How fearful are you about crime in your neighborhood?" "How safe is it to walk around alone in your neighborhood during the daytime?," "How safe is it to walk around alone in your neighborhood after dark?," and "Compared to other neighborhoods, the crime rate in my neighborhood is...(Very High to Very Low)". This scale had a Cronbach's alpha of .83 .

Respondents' depressive symptoms were assessed with three items from the BSI-18 depression subscale (Derogatis 2001) asking how often respondents felt lonely, blue or sad, and having no interest in things (Cronbach's alpha = .77). Respondents' perceived stress levels was assessed with three items (adapted from Cohen et al. 1983) asking 
how often respondents felt upset because of something unexpected happening, nervous and stressed out, and they had so many problems that they could not deal with them $($ Cronbach's alpha $=.73)$.

\section{Ratings of Neighborhood Physical Conditions}

Data on neighborhood physical conditions in Flint were obtained from the Flint Environmental Block Assessment (EBA) (For detailed description, methods, and materials, see: http://www.flinteba.org). The original EBA was developed in the late 1960s by the American Public Health Association to assess housing quality by conducting a "sidewalk" survey and evaluation of a community's housing stock. The current EBA project was conducted by researchers at the University of Michigan-Flint and assessed all of nearly 60,000 real estate parcels located within Flint in 2000. Urban Planning and Geographic Information Systems consultants from the University of Michigan's Ann Arbor campus and community advisors developed assessment tools for neighborhood structures. Trained field assessment workers rated each parcel on a scale from 0 to 25 based on the condition of the building foundation, exterior surfaces, stairs, rails, porches, roofs, gutters, downspouts, chimneys, windows, doors, and landscaping. Internal consistency reliabilities (Cronbach's alpha) for total scores were .70 for residential structures and .94 for commercial structures. Structures with scores from 5-9 were defined as being in "major disrepair" (1\% of residential and $16 \%$ of commercial structures) and those scoring between $0-4$ were defined as "not salvageable ( $0.2 \%$ of residential and $1.8 \%$ of commercial structures).

The pattern of zero-order correlations among these telephone survey measures and the independent EBA neighborhood condition ratings (see Table 3) suggest these brief measures have adequate convergent and divergent validity. The correlations among the respondents' ratings of their neighborhood (satisfaction, social contact, social capital, fear of crime) were low (.12) to moderate (-.46) as expected. These measures were generally less correlated with the independent ratings of neighborhood conditions (range: -.04 to .22 ) and with mental health symptom ratings (range: -.11 to .27 ). The two mental health measures (depression and stress) had the highest observed correlation (.53).

We operationalize "neighborhoods" as buffer zones around a respondent's home. We used Geographical Information Systems (GIS) software to locate the addresses of survey respondents and selected residential and commercial structures on a map of Flint. We divided data into 6 areas separated by natural edges, including the Flint River and limited access highways. We calculated the number of residential and commercial structures classified as in major disrepair or not salvageable within four different radii of respondents, $.25, .45, .62(1 \mathrm{~km})$ and 1.0 miles. The "rule of thumb" for examining effects of the built environment is a distance of 0.25 miles (Institute of Medicine Transportation Research Board 2005), which is based on a Bayesian model of critical acceptable pedestrian walking distances (Seneviratne 1985). We found that the spatial autocorrelation, or clustering, of dilapidated structures reached a maximum at 0.45 miles (Moran's Index $=0.0215$, Z-score of standard deviations $=2.53$ ). About $1 \mathrm{~km}$ and one mile radii were also considered because of their common usage. We used the log of these counts due to the skewness of the counts, with 0 transformed to .1, for analyses. Deterioration of non-residential properties has been found to have a greater impact on fear of crime than deterioration of residential properties (Perkins and Taylor 1996). Thus, data for residential and commercial structures were analyzed separately. We combined the number of residential structures listed as vacant and in major disrepair or not salvageable $($ alpha $=.70)$ and the number of commercial structures listed as vacant and in major disrepair or not salvageable $($ alpha $=.94)$, to create two indicators of neighborhood physical deterioration.

In correspondence with prior literature (Institute of Medicine Transportation Research Board 2005), analyses comparing the four radii suggested that a 0.25 mile radius is an appropriate buffer from which to examine residential deterioration (Table 1). This distance had the highest correspondence with social capital and fear of crime, although reported social contact was equivalent for 0.25 and 0.45 miles and neighborhood satisfaction was maximized at 0.45 miles. Because 0.25 generally retains a stronger association with perception measures and to retain comparability with prior research, we operationalize neighborhoods with the 0.25 mile radius.

The data also suggest that $1 \mathrm{~km}$ was appropriate for examining commercial deterioration (Table 1). Correlations between deterioration of commercial structures were stronger at $1 \mathrm{~km}$ than for the shorter distances. Deterioration at $1 \mathrm{~km}$ generally showed stronger associations with study measures than at one mile. There were two differences, between $1 \mathrm{~km}$ and one mile: (1) social contact was not associated with commercial deterioration at $1 \mathrm{~km}$, but was associated with deterioration at one mile; (2) stress was associated with deterioration at $1 \mathrm{~km}$, but not at one mile. Because of the generally stronger associations at $1 \mathrm{~km}$ with most study measures and because of the significant association with the stress $1 \mathrm{~km}$ was chosen over one mile.

Thus, based on these empirical analyses, we considered residential deterioration within a $0.25 \mathrm{~km}$ radius of the participant and commercial deterioration within a $1 \mathrm{~km}$ radius for our subsequent analyses. 
Table 1 Zero-order correlations between measures of residential deterioration a and neighborhood perceptions by radius from respondent's home

\begin{tabular}{|c|c|c|c|c|c|c|}
\hline Radius from respondent's home & Social contact & Social capital & Fear of crime & Satisfaction & Stress & Depressive symptoms \\
\hline \multicolumn{7}{|l|}{ Residential structures } \\
\hline 0.25 Mile & $-.109 * *$ & $-.141 * * *$ & $.222 * * *$ & $-.162 * * *$ & $.070 *$ & .039 \\
\hline 0.45 Mile & $-.109 * *$ & $-.132 * * *$ & $.197 * * *$ & $-.168 * * *$ & $.078^{*}$ & .014 \\
\hline 0.62 Mile $(1 \mathrm{~km})$ & $-.083^{*}$ & $-.118 * * *$ & $.187 * * *$ & $-.154 * * *$ & .057 & .010 \\
\hline 1.0 Mile & $-.107 * *$ & $-.163 * *$ & $.193 * * *$ & $-.167 * * *$ & .047 & .020 \\
\hline \multicolumn{7}{|l|}{ Commercial structures } \\
\hline 0.25 Mile & -.041 & -.044 & .068 & $-.105 * *$ & .055 & .028 \\
\hline 0.45 Mile & -.063 & $-.111 *$ & $.131 *$ & $-.124 * * *$ & $.108 * *$ & .068 \\
\hline .62 Mile $(1 \mathrm{~km})$ & -.059 & $-.130^{*}$ & $.178^{*}$ & $-.146 * * *$ & $.078^{*}$ & .052 \\
\hline 1.0 Mile & $-.089^{*}$ & $-.107 * *$ & $.170 * * *$ & $-.096^{*}$ & .067 & .058 \\
\hline
\end{tabular}

Note: $N=801 ; * p<.05, * * p<.01, * * * p<.001$

a Deterioration was defined as the log count of dilapidated structures

\section{Data Analyses}

Associations between demographic factors and mental health outcomes are well known. Researchers have also reported demographic associations with predictors used in our model. For example, fear of crime is higher for women than men (Perkins and Taylor 1996), older individuals than younger individuals (Skogan and Maxfield 1981), and individuals with less education than for those with more education (Austin et al. 1994).

Our analyses employ structural equation modeling to investigate the potential causal pathways between study measures. We used LISREL to create a path model from the covariance matrix of the variables of interest with the variance accounted for by the demographic variables removed. This model predicted neighborhood satisfaction, neighborhood social contact, neighborhood social capital, and fear of crime with the two indicators of neighborhood physical deterioration with radii samples of 0.25 mile. Fear of crime and neighborhood satisfaction were allowed to mediate the impact of neighborhood social contact and neighborhood social capital, as well as having direct effects. We also tested for direct effects of neighborhood deterioration on depressive symptoms and stress. Nonsignificant paths were trimmed from the model (See Fig. 1).

An alternative approach is to use multi-level modeling, such as through Hierarchical Linear Modeling (HLM). (HLM; Raudenbush and Bryk 2002). While our data are conceptually multi-level, they do not lend themselves to the hierarchical linear modeling approach for two reasons. First, our definition of "neighborhood" is based on a geographic buffer around each individual respondent's home; that buffer-based neighborhood may approximate the respondent's daily experiences and exposures more accurately than an administratively-defined census tract.
This operationalization means essentially that each "neighborhood" is uniquely defined for each survey respondent (Personal communication: Ana Diez-Roux, April 20, 2006). In these situations, researchers of neighborhood conditions often use other techniques that account for potential issues associated with shared measurement variance (Lee and Cubbin 2002; Zenk et al. 2005) such as through structural equation modeling (Pachter et al. 2006). For example, Latkin and colleagues (2005) used structural equation modeling to examine how neighborhood social disorder predicts injection drug use. Second, we performed a preliminary analysis that did approach this analysis from a multi-level perspective. Specifically, we modeled individual responses at level one and census-tract defined neighborhoods at level two using the HLM 6.02a software. This assumes that there is a meaningful level of shared variance within a given census tract. The unconditional intra-class coefficients for our outcomes of interest, depressive symptoms and stress, were 0.013 and 0.017 , respectively. This means that only $1.3 \%$ and $1.7 \%$ of the variance in depressive symptoms and stress were between census tracts, with the remaining $98.7 \%$ and $98.3 \%$ of the variance occurring at the individual level. These findings support the notion that census tracts may not be optimal units for our research questions. Additionally, since most of the variation is at the individual level, modeling covariates at the individual level using SEM approaches is a reasonable method for the present study.

\section{Results}

As expected, demographic factors were significantly related to the predictor and outcome variables of interest (See Table 2). Older respondents reported higher levels of neighborhood satisfaction, social capital, and lower levels 
of stress and depressive symptoms than younger respondents. There were no gender differences in any of these measures. Married persons lived in neighborhoods with a lower concentration of residential deterioration, reported higher neighborhood social capital, reported less fear of crime, less stress and fewer depressive symptoms than unmarried respondents. Those with higher levels of education experienced lower concentrations of residential and commercial deterioration, greater social contact and social capital, lower fear of crime, greater neighborhood satisfaction, and fewer depressive symptoms than those with less education. African Americans lived in areas with a higher concentration of residential deterioration and reported less social contact with neighbors than did White respondents. However, there were no racial differences in other dimensions, including fear of crime, neighborhood satisfaction, stress and depression. Those who were unemployed experienced a higher concentration of residential deterioration, lower levels of social contact with neighbors and social capital, and greater fear of crime, stress, and depressive symptoms. Demographic factors accounted for $8 \%$ of the variance in stress and $6 \%$ of the variance in depressive symptoms.

Among the predictor and outcome variables of interest, residential deterioration was positively correlated with commercial deterioration, fear of crime, and stress and negatively correlated with neighborhood satisfaction, social contact, and social capital. Residential deterioration was not associated with depressive symptoms, however. Commercial deterioration was negatively correlated with neighborhood social capital and neighborhood satisfaction, and positively correlated with fear of crime and stress. These patterns of relationships were found when demographic factors were partialed out of these relationships, except that residential and commercial deterioration were no longer correlated with stress (See Table 3).
The path model indicated significant unique inverse relationships between residential deterioration and neighborhood social contact; and between social capital and fear of crime (See Fig. 1). Commercial deterioration was directly related to fear of neighborhood crime. Residential deterioration and commercial deterioration shared $4 \%$ of their variances.

Neighborhood social contact was directly related to neighborhood social capital. Neighborhood social capital was directly related to neighborhood satisfaction, and inversely to fear of crime, stress, and depressive symptoms. Fear of crime predicted neighborhood satisfaction, stress, and depressive symptoms. Stress and depressive symptoms shared $22 \%$ of their variances. All predictions were in the expected direction.

This model had an excellent fit to the data, as indicated by the goodness of fit indicators (see Table 4). This includes a non-significant value for the Chi-Square, which tests whether the pattern of the data significantly differs from the theoretical model. Adding direct effects of residential and commercial deterioration to stress and depressive symptoms did not produce a better fit with the data (see Table 4).

The alternative socialization mediation model, Model 2, tested whether the impact of neighborhood conditions on depressive symptoms and stress is mediated by social contact with neighbors (See Fig. 2). Thus, structural deterioration would predict social capital, fear of crime, and neighborhood satisfaction; which in turn would predict, neighborhood social contact, which would predict depressive symptoms and stress. Models 1 and 2 are not nested models, so the change in fitness cannot be tested directly. However, Model 2 was not a good fit to the data, as indicated by the statistically significant $\chi^{2}$ and less favorable values on other goodness of fit indicators (see Table 4).

Table 2 Demographic means, standard deviations, and correlations with path model variables

\begin{tabular}{lcccccc}
\hline & Age & Sex & Marital status & Education & Race & Employment status \\
\hline Residential deterioration & -.007 & -.033 & $-.143^{* * *}$ & $-.176^{* * *}$ & $.240^{* * *}$ & $.069 *$ \\
Commercial deterioration & -.026 & -.003 & -.056 & $-.092^{* *}$ & .010 & .038 \\
Neighborhood Social contact & .023 & .049 & .041 & $.108^{* *}$ & $-.076^{*}$ & $-.072^{* *}$ \\
Neighborhood social capital & $.154^{* * *}$ & .023 & $.113^{*}$ & $.137^{* * *}$ & -.056 & $-.133^{* * *}$ \\
Neighborhood satisfaction & $.092^{*}$ & -.010 & .036 & $.132^{* * *}$ & -.019 & -.047 \\
Fear of crime & -.068 & -.053 & $-.075^{*}$ & $-.110^{* *}$ & .022 & $.082^{*}$ \\
Stress & $-.222^{* * *}$ & -.066 & $-.080^{*}$ & $-.098^{* *}$ & -.030 & $.153^{* * *}$ \\
Depressive symptoms & $-.074 *$ & -.013 & $-.191^{*}$ & $-.119 * *$ & -.003 & $.108^{* *}$ \\
$M$ & 45.25 & .31 & .38 & 12.82 & .57 & .18 \\
$S D$ & 16.92 & .46 & .48 & 1.82 & .50 & .39 \\
\hline
\end{tabular}

Note: $N=546 ; * p<.05, * * p<.01, * * * p<.001$. For sex, female $=0$ and male $=1$; for race, White $=0$ and African American $=1$; for employment status, employed $=0$ and unemployed $=1$. Deterioration is the log of the deteriorated structure count at 0.25 miles 
Table 3 Means, standard deviations, and correlations among path model variables

\begin{tabular}{|c|c|c|c|c|c|c|c|c|}
\hline & 1 & 2 & 3 & 4 & 5 & 6 & 7 & 8 \\
\hline \multirow[t]{2}{*}{ 1. Residential deterioration } & \multirow[t]{2}{*}{-} & $.210 * * *$ & $-.109 * * *$ & $-.141 * *$ & $-.162 * * *$ & $.222 * * *$ & $.070 *$ & .039 \\
\hline & & $.199 * * *$ & $-.074 *$ & $-.103 * *$ & $-.144 * * *$ & $.203 * * *$ & .054 & .002 \\
\hline \multirow[t]{2}{*}{ 2. Commercial deterioration } & & - & -.059 & $-.130 * * *$ & $-.146 * * *$ & $.178 * * *$ & $.078 *$ & .052 \\
\hline & & & -.047 & $-.111 * *$ & $-.133 * * *$ & $.165 * * *$ & .061 & .030 \\
\hline \multirow[t]{2}{*}{ 3. Neighborhood social contact } & & & - & $.289 * *$ & $.121 * * *$ & $-.152 * * *$ & $-.092 * * *$ & $-.113 * *$ \\
\hline & & & & $.271 * *$ & $.106 * *$ & $-.135 * * *$ & $-.072 *$ & $-.095 * *$ \\
\hline \multirow[t]{2}{*}{ 4. Neighborhood social capital } & & & & - & $.434 * * *$ & $-.436 * * *$ & $-.223 * * *$ & $-.215 * * *$ \\
\hline & & & & & $.417 * * *$ & $-.417 * * *$ & $-.173 * * *$ & $-.176 * * *$ \\
\hline \multirow[t]{2}{*}{ 5. Neighborhood satisfaction } & & & & & - & $-.459 * * *$ & $-.202 * * *$ & $-.148 * * *$ \\
\hline & & & & & & $-.448 * * *$ & $-.176^{* * *}$ & $-.128 * *$ \\
\hline \multirow[t]{2}{*}{ 6. Fear of crime } & & & & & & - & $.274 * * *$ & $.198 * * *$ \\
\hline & & & & & & & $.248 * * *$ & $.171 * * *$ \\
\hline \multirow[t]{2}{*}{ 7. Stress } & & & & & & & - & $.534 * * *$ \\
\hline & & & & & & & & $.521 * * *$ \\
\hline 8. Depressive symptoms & & & & & & & & - \\
\hline$M$ & .04 & .66 & 2.49 & 5.50 & 2.74 & 2.23 & 8.21 & 5.93 \\
\hline$S D$ & .81 & .61 & 1.07 & 1.41 & .82 & .64 & 2.90 & 2.89 \\
\hline
\end{tabular}

Note: $N=801 ; * p<.05, * * p<.01, * * * p<.001$. Partial correlations among variables controlling for demographic influences are in italics

Table 4 Goodness of fit statistics for path models

\begin{tabular}{|c|c|c|c|c|c|c|c|c|c|}
\hline Model & $\chi^{2}$ & d.f. & $\chi^{2} /$ d.f. & RSMEA & SRMR & GFI & NFI & IFI & $\mathrm{CN}$ \\
\hline Model 1 & 17.95 & 15 & 1.197 & 0.016 & 0.028 & .99 & .98 & 1.00 & 1357 \\
\hline Direct effects on Mental Health & 16.09 & 11 & 1.463 & 0.024 & 0.027 & .99 & .98 & .99 & 1218 \\
\hline Comparison to Model 1 & & 4 & & $\Delta \chi^{2}(4)=$ & $p>.75$ & & & & \\
\hline Model 2 & 75.85 & 17 & 4.462 & 0.066 & 0.076 & .98 & .93 & .94 & 344 \\
\hline
\end{tabular}

\section{Discussion}

Past research has found that the physical decay of neighborhoods is associated with negative outcomes such as disease and fear of crime (Box et al. 1988; Cohen et al. 2000; Lewis and Maxfield 1980; Perkins and Taylor 1996; Skogan and Maxfield 1981). The present study found indirect associations between structural deterioration and mental health outcomes such as perceived stress and depressive symptoms. These associations were mediated by social behavior and by neighborhood perceptions. Two competing causal models were explored.

The model that best fit the data showed that the association between neighborhood deterioration and mental health was mediated by both individual perceptions and social behaviors. The model specified that residential property deterioration was directly associated with reduced social contact in the neighborhood and greater fear of neighborhood crime. Commercial deterioration was also directly associated with fear of neighborhood crime. Not surprisingly, neighborhood social contact was associated with increased perceptions of neighborhood social capital.
Social capital was in turn negatively correlated with fear of crime in the neighborhood. Fear of crime was associated with lower neighborhood satisfaction and higher perceived stress and higher depressive symptoms. Neighborhood social capital was inversely related to stress and depressive symptoms.

A competing second model adopted a different causal order, but did not fit the data as well as the first model. The second model suggested that neighborhood deterioration indirectly influenced mental health outcomes by directly changing perceptions of one's neighborhood (e.g., fear of crime, social capital, satisfaction) and in turn, these perceptions would lead to changes in social contact. After exploring these competing models, we conclude that the indirect effects of neighborhood deterioration were more likely to be mediated by social behaviors (as defined by social contact) influencing neighborhood perceptions rather than neighborhood perceptions influencing social behavior.

We tested other possible specifications of the model. One important alternative included direct paths from residential deterioration to mental health outcomes. Some research suggests that neighborhood physical hazards may 
be associated with depression and stress (Stallones and Bresler 2002; Savi et al. 2003). However, the absence of such a direct path in the present study highlights the centrality of psychosocial mediators.

Our analyses suggest that a key consequence of neighborhood deterioration, as measured by this study, is decreased contact with one's neighbors and increased concerns with safety. These results suggest that community-level interventions for preventing mental health problems in deteriorating neighborhoods should promote social contact among neighbors and prevent the deterioration of the neighborhoods themselves. Promoting social contact may lead to more positive perceptions of one's neighborhood and improved mental health. However, although our findings suggest that neighborhood deterioration influence mental health through a mediated pathway, deterioration may have important direct effect on other outcomes, such as financial losses (e.g. decreasing property values) and unintentional injuries.

Our findings are not surprising, given the previous literature. It has long been suggested that neighborhood disorder can lead to broken social ties, crime, and anomie (Park and Burgess 1925; Hunter 1974). Recent studies confirm these relationships and further suggest that social ties and positive interpersonal relationships mediate the relationships between neighborhood conditions and crime (Sampson et al. 1997; 1999; Saegert and Winkel 2004). In addition to crime itself, perceptions of safety and fears of crime may be influenced by social ties. Ross and Jang (2000) report that one's social ties with neighbors buffers the effects of neighborhood disorder on fear and mistrust, a notion supported by our results. Ross (2000) further finds that measures of neighborhood disorder are associated with depression and mediated by individual perceptions of neighborhood disorder.

Finally, an important aspect of our analysis is in the operationalization of "neighborhood." In this analysis, we did not use the most commonly used unit of neighborhood, the census tract. Rather, we examined a zone that was unique to each respondent. Our analyses suggested that a 0.25 and 0.62 mile $(1 \mathrm{~km})$ zone around each respondent were useful for examining residential and commercial deterioration, respectively. It seems reasonable that individuals are influenced by a smaller residential zone than a commercial zone since most individuals do not live as close to commercial enterprises as to other residences. Moreover, these findings suggest that a "one size fits all" approach for defining neighborhood (such as commonly used analyses of census tracts) may be suboptimal. Future research should contrast both empirically derived "objective" definitions of neighborhoods with perceptual neighborhood boundaries. Likely, the optimal definition of a neighborhood will depend on the construct of interest. As our data indicates, it may also be appropriate to consider different neighborhood boundaries for different constructs.

As with all research, a few caveats should be noted. First, the data are cross-sectional and therefore, we are unable to firmly establish the temporal ordering of study variables. Our use of path analysis and the testing of alternative models suggests our hypothetical causal order of constructs is supported, but stronger evidence for establishing causal paths requires longitudinal data and more opportunities to test alternative causal explanations. Second, our interest was in psychological stress and depressive symptoms as more general markers of quality of life. Our findings cannot be generalized to clinical diagnoses such as major depression. Third, our survey had a low response rate and may have introduced sampling biases. This low response rate was balanced by a novel and systematic assessment of all land parcels around the respondent's. Fourth, our findings are based on one industrial city in the U.S. "rust belt", and although this is a demographically diverse community, it is not known how well these results may generalize to other settings. In balance, the study has several strengths, including the geocoding of participants from a systematic sample of the general population and the use of standardized "objective" criteria in defining neighborhood deterioration.

Should the findings of this research be replicable, enduring and causal, it suggests that interventions targeted at improving neighborhood social and physical conditions may lessen the burden of stress and depressive symptoms as well as improve relationships between neighbors. The identification of social contact, social capital, fear of crime, and neighborhood satisfaction as mediators of the relationship between residential deterioration and mental health does not imply a stopping point. Future research needs to identify the reasons why neighborhoods deteriorate, reduce the harmful impact of living in dilapidated neighborhoods, and find effective means of preventing neighborhood decay

Acknowledgements The Speak to Your Health! Community Survey was supported by the Prevention Research Center of Michigan (Centers for Disease Control and Prevention Grant No. U48/ CCU515775) and the Genesee County Health Department. We would like to thank Survey Committee members for their assistance, and all those who participated in the project.

\section{References}

Aneshensel, C. S., \& Sucoff, C. A. (1996). The neighborhood context of adolescent mental health. Journal of Health and Social Behavior, 37, 293-310.

Austin, D. M., Furr, L. A., \& Spine, M. (2002). The Effects of Neighborhood Conditions on Perceptions of Safety. Journal of Criminal Justice, 30, 417-427. 
Austin, D. M., Woolever, C., \& Baba, Y. (1994). Crime and safetyrelated concerns in a small community. American Journal of Criminal Justice, 19, 79-97.

Baba, Y., \& Austin, D. M. (1989). Neighborhood environmental satisfaction, victimization and social participation as determinants of perceived neighborhood safety. Environment and Behavior, 21, 763-780.

Baum, A., Singer, J. E., \& Baum, C. S. (1981). Stress and the environment. Journal of Social Issues, 37, 4-35.

Box, S., Hale, C., \& Andrews, G., (1988). Explaining fear of crime. British Journal of Criminology, 28, 340-356.

Bronzaft, A. L., \& McCarthy, D. P. (1975). The effect of elevated train noise on reading ability. Environment and Behavior, 7 , 517-528.

Browning, C. R., \& Cagney, K. A. (2002). Neighborhood structural disadvantage, collective efficacy, and self-rate physical health in an urban setting. Journal of Health and Social Behavior, 43, $383-400$

Cohen, D., Spear, S., Scribner, R., Kissinger, P., Mason, K., \& Wildgen, J. (2000). "Broken windows" and the risk of gonorrhea. American Journal of Public Health, 90, 230-236.

Cohen, S., Kamarck, T., \& Mermelstein, R. (1983). A global measure of perceived stress. Journal of Health and Social Behavior, 24, 385-396.

Coleman, J. S. (1990). The foundations of social theory. Cambridge: Harvard University Press.

Damon, W. (1977). The social world of the child. San Francisco: Jossey-Bass.

Derogatis, L. R. (2001). Brief symptom inventory-18 (bsi-18) administration, scoring, and procedures manual. Minneapolis: NCS Pearson.

Ellen, J.M., Jennings, J.M., Meyers, T., Chung, S., \& Taylor, R. (2004). Perceived social cohesion and prevalence of sexually transmitted diseases. Sexually Transmitted Diseases, 31, 117122.

Faris, R., \& Dunham, H. W. (1939). Mental disorders in urban areas. Chicago: University of Chicago Press.

Farrell, S. J., Aubry, T., \& Coulombe, T. A. (2004). Neighborhoods and neighbors: Do they contribute to personal well-being. Journal of Community Psychology, 32, 9-25.

Furstenburg, F. F. (1993). How families manage risk and opportunity in dangerous neighborhoods. In W. J. Wilson (Ed.), Sociology and the public agenda (pp. 231-258). Newbury Park: Sage.

Garbarino, J., \& Kostelny, K. (1992). Child maltreatment as a community problem. Child Abuse and Neglect, 16, 455-464.

Gee, G., \& Payne-Sturges, D. (2004). Environmental health disparities: A framework integrating psychosocial and environmental concepts. Environmental Health Perspectives, 112, $1645-1653$.

Huckfeldt, R. R. (1983). Social contexts, social networks and urban neighborhoods: Environmental constraints on friendship choice. American Journal of Sociology, 89, 652-669.

Hunter, A. (1974). Symbolic communities. Chicago: University of Chicago Press.

Institute of Medicine Transportation Research Board (2005). Does the built environment influence physical activity? examining the evidence. TRB special report 282. Washington: Author.

Kawachi, I., Kennedy, B. P., \& Wilkinson, R.G. (1999). Crime: Social disorganization and relative deprivation. Social Science \& Medicine, 48, 719-731.

Latkin, C. A., Williams, C. T., Wang, J., \& curry, A. D. (2005). Neighborhood social disorder as a determinant of drug injection behaviors: A structural equation modeling approach. Health Psychology, 24, 96-100.

Lazarus, R. S. (1999). Stress and emotion: A new synthesis. New York: Springer.
Lazarus, R. S., \& Folkman, S. (1984). Stress, appraisal and coping. New York: Springer.

Lee, R.E., Cubbin C. (2002). Neighborhood context and youth cardiovascular health behaviors. American Journal of Public Health 92, 428-436.

Leventhal, T., \& Brooks-Gunn, J. (2003). Children and youth in neighborhood contexts. Current Directions in Psychological Science, 12, 27-31.

Lewis, D.A., \& Maxfield, M.G. (1980). Fear in the neighborhoods: An investigation of the impact of crime. Journal of Research and Crime and Delinquency, 17, 160-189.

Park, R. E., \& Burgess, E. W. (1925). The city. Chicago: University of Chicago Press.

Pachter, L.M., Auinger, P, Palmer R, \& Weitzman, M. (2006). Do parenting and the home environment, maternal depression, neighborhood, and chronic poverty affect child behavioral problems differently in different racial-ethnic groups? Pediatrics, 117, 1329-1338.

Perkins, D. G., \& Taylor, R. B. (1996). Ecological assessments of community disorder: Their relationship to fear of crime and theoretical implications. American Journal of Community Psychology, 24, 63-107.

Prezza, M., Amici, M., Roberti, T., \& Tedeschi, G. (2001). Sense of community referred to the whole town: Its relations with neighboring, loneliness, life satisfaction and area of residence. Journal of Community Psychology, 29, 29-52.

Putnam, R. D. (1993). Making democracy work: Civic traditions in modern italy. Princeton: Princeton University Press.

Raudenbush, S. W., \& Bryk, A. S. (2002). Hierarchical linear models: Applications and data analysis methods. Thousand Oaks: Sage Publications.

Ross, C. E. (2000). Neighborhood disadvantage and adult depression. Journal of Health and Social Behavior, 41, 177-187.

Ross, C. E., \& Mirowsky, J. (1999). Disorder and decay: The concept and measurement of perceived neighborhood disorder. Urban Affairs Review, 34, 412-432.

Ross, C. E., \& Mirowsky, J. (2001). Neighborhood disadvantage, disorder, and health. Journal of Health and Social Behavior, 42, 258-276.

Ross, C.E., \& Jang, S.J. (2000). Neighborhood disorder, fear, and mistrust: The buffering role of social ties with neighbors. American Journal of Community Psychology, 28, 401-420.

Saegert, S., \& Winkel, G. (2004). Crime, social capital, and community participation. American Journal of Community Psychology, 34, 219-233.

Sampson, R. J. (1995). The community. In J. Q. Wilson \& J. Petersilia (Eds.), Crime (pp. 193-216). San Francisco: Institute for Contemporary Studies.

Sampson, R. J., Morenoff, J. D., \& Earls, F. (1999). Beyond social capital: Spatial dynamics of collective efficacy for children. American Sociological Review, 64, 633-660.

Sampson, R. J., Raudenbush, S. W., Earls, F. (1997). Neighborhoods and violent crime: A multilevel study of collective efficacy. Science, 227, 918-923.

Sandler, I. N., Wolchik, S. A., MacKinnon, D., Ayers, T. S., \& Roosa, M. W. (1997). Developing linkages between theory and intervention in stress, coping processes. In S. A. Wolchik \& I. N Sandler (Eds.), Handbook of children's coping: Linking theory and intervention (pp. 3-41). New York: Plenum.

Savi, R. M., Lara, D. R., Ghisolfi, E. S., Portela, L. V., Dias, R. D., \& Souza, D. O. (2003). Neuropsychiatric evaluation in subjects chronically exposed to organophosphate pesticides. Toxicological Sciences, 72, 267-271.

Seneviratne, P. N. (1985). Acceptable walking distances in central areas. Journal of Transportation Engineering, 3, 365-376.

Skogan, W. (1991). Disorder and decline. New York: Free Press. 
Skogan, W. G., \& Maxfield, M. G. (1981). Coping with crime. Newbury Park: Sage.

Smith, S. K., Steadman, G. W., Minton, T. D., \& Townsend, M. (1999). Criminal victimization and perceptions of community safety in 12 cities, 1998. Bureau of Justice Statistics and Office of Community Oriented Policing Services, US Department of Justice. Available at http://www.ojp.usdoj.gov/bjs/pub/pdf/ cvpcs98.pdf, accessed on April 20, 2005.

Stallones, L., \& Breseler C. (2002). Pesticide poisoning and depressive symptoms among farm residents. Annals of Epidemiology, 12, 389-394.

Taylor, R. B. (2001). Breaking away from broken windows: Evidence from Baltimore neighborhoods and the nationwide fight against crime, grime, fear, and decline. Boulder: Westview Press.

Taylor, R. B., Shumaker, S. A., \& Gottfredson, S. D. (1985). Neighborhood-level links between physical features and local sentiments: Deterioration, fear of crime, and confidence. Journal of Architectural Planning and Research, 2, 261-275.

U.S. Census. (2001a). Census 2000 Summary File 1. Washington, Author. Available at: http://factfinder.census.gov/, accessed on April 20, 2005.

U.S. Census. (2001b). Census 2000 Summary File 3. Washington, Author. Available at: http://factfinder.census.gov/, accessed on April 20, 2005.
Wandersman, A., Andrews, A. B., Riddle, D., \& Fawcett, C. (1983). Environmental psychology and prevention. In R. D. Felner, L. A. Jason, J. N. Moritsugu, \& S. S. Farber (Eds.), Preventive psychology: Theory, research and practice (pp. 104-127). New York: Pergamon Press.

Wandersman, A., \& Nation, M. (1998). Psychological contributions to understanding toxicity, resilience, and interventions. American Psychologist, 53, 647-656.

Weenig, M. W. H., Schmidt, T., \& Midden, C. J. H. (1990). Social dimensions of neighborhoods and the effectiveness of information programs. Environment and Behavior, 22, 27-54.

White, M., Kasl, S. V., Zahner, G. E. P., \& Will, J. C. (1987). Perceived crime in the neighborhood and mental health of women and children. Environment and Behavior, 19, 588-613.

Wiesenfeld, E. (1996). The concept of "we": A community social psychology myth? Journal of Community Psychology, 24, 337345.

Zenk, S. N., Schulz, A. J., Israel, B. A., James, S. A., Bao, S., \& Wilson, M. L. (2005). Neighborhood racial composition, neighborhood poverty, and the spatial accessibility of supermarkets in metropolitan Detroit. American Journal of Public Health, 95, 660-667. 